University of Nebraska - Lincoln

DigitalCommons@University of Nebraska - Lincoln

Faculty Publications, Department of Psychology

Psychology, Department of

1997

\title{
Autobiographical Misremembering: John Dean Is Not Alone
}

Robert F. Belli

University of Nebraska-Lincoln, bbelli2@unl.edu

Howard Schuman

University of Michigan

Benita Jackson

University of Michigan

Follow this and additional works at: https://digitalcommons.unl.edu/psychfacpub

Part of the Psychiatry and Psychology Commons

Belli, Robert F.; Schuman, Howard; and Jackson, Benita, "Autobiographical Misremembering: John Dean Is Not Alone" (1997). Faculty Publications, Department of Psychology. 481.

https://digitalcommons.unl.edu/psychfacpub/481

This Article is brought to you for free and open access by the Psychology, Department of at DigitalCommons@University of Nebraska - Lincoln. It has been accepted for inclusion in Faculty Publications, Department of Psychology by an authorized administrator of DigitalCommons@University of Nebraska - Lincoln. 
Published in Applied Cognitive Psychology 11 (1997), pp. 187-209.

Copyright (C) 1997 by John Wiley \& Sons, Ltd. Used by permission.

Portions of this manuscript are based on a presentation given at the American Association for Public Opinion meeting in Ford Lauderdale, in May, 1995. We would like to thank Steve Blixt for his assistance during the formative stages of this research.

\title{
Autobiographical Misremembering: John Dean Is Not Alone
}

\author{
Robert F. Belli, Howard Schuman, and Benita Jackson \\ University of Michigan \\ Corresponding author - Bob Belli, Institute for Social Research, \\ University of Michigan, Ann Arbor, MI 48106-1248, USA
}

\begin{abstract}
Survey respondents were asked to provide knowledge responses to public events and names that occurred as long ago as the 1930s and as recently as the 1980s. Respondents made errors that reflect the use of semantic and lexical memory systems, and reconstructive processes based on a semantic theme. Errors, as well as correct responses, are affected by whether the events originally occurred during the transition phase (early teens to mid-twenties). Responses indicate that events that occur during the transition phase are remembered better than events that occur during other life phases (in contradiction to the differential sampling hypothesis), but that events that occur during the transition phase can also promote error-prone reporting by interfering with other events or by promoting inaccurate reconstructions. The evidence suggests that the transition phase is not a monolithic entity, but that young adolescence differs from older transition phase ages by having a greater concentration on determining general properties of the world. Support is strongest for cognitive accounts of transition phase effects such as the first experience hypothesis, and results challenge physiological and evolutionary accounts that are tied to the transition phase promoting better memory. Finally, the more dramatic observed errors (such as inverting the subject and object of an event) point to possible undocumented instances of autobiographical misremembering.
\end{abstract}

\section{Introduction}

Many students of autobiographical memory have a particular interest in John Dean, Richard Nixon's counsel during the Watergate scandal, because Dean's memory of some of the events surrounding Watergate has been used as an instructive case study (Neisser, 1981). Dean was found, not only to provide some faithful descriptions of events, but he also made errors that offered insight into the manner in which events are conceptualized and prioritized in memory. In this paper, we continue to explore the contribution that John Dean provides to an increased understanding of autobiographical memory, though we are not interested in Dean's own memory. Rather, we focus on the errors that a representative sample 
of adult Americans make while remembering John Dean, other public figures such as Joe McCarthy, and national events such as the Tet Offensive.

In examining respondent errors, we started with two interests. First, we sought to identify the different types of errors that were made, in order to gain insight into the basic memory processes that lead to error-prone reports. Second, in an extension of prior work (Schuman, Belli and Bischoping, 1997) that found agerelated cohort effects with correct responses, we sought to determine whether cohort effects also occur with errors.

\section{Different error types}

We observed a variety of errors in people's reports, and document several types. First, it is important to acknowledge that some responses were not actually wrong, but were initially classified as errors because they did not fit the intended target of the investigators. For example, when asked about Joe McCarthy, some respondents reported not the notorious Senator from the 1950s, but a New York Yankees baseball manager from the 1940s, and in trying to identify Woodstock, some reported a cartoon character rather than a 1969 rock concert. Second, some erroneous responses seemed to reflect guesses that were constructed by using phrases or words in the question as lexical cues that were then associated with some unrelated event with which they were familiar. For example, a number of people when asked about John Dean remembered the actor James Dean and others remembered the singer Jimmy Dean. Third, some errors were semantically related to the target but referred to events that occurred either at an earlier or later time, such as people reporting the Vietnam War's Tet Offensive of the 1960s to be part of the Korean conflict of the 1950s or the Iraqi-American conflict of 1990. Fourth are errors that included the important components of an event but inverted the subject- object relationship, such as respondents who remembered Joe McCarthy, the senator who sought to expose communists, as a senator who was accused of being a communist! Other error types will also be identified. Like the errors in John Dean's memory of the Watergate affair, the errors that people make in remembering public events across the lifespan are instructive regarding how memory serves to conceptualize and prioritize the world.

\section{Lifespan memory: transition phase effects}

Another of our primary interests in exploring respondent errors is to gain additional insight into age trend effects found with lifespan memory. An important discovery in lifespan memory research is that events that occur during the life transition from childhood to adulthood (early teens to middle twenties, hereafter referred to as the transition phase) are more often remembered than events that occur during other phases of people's lives, with the exception of very recent events. This transition phase effect has been found with a number of different approaches. Some of these studies have provided subjects with cue words (e.g. cat, flag) and instructions to revive an autobiographical experience to each word (Fitzgerald and Lawrence, 1984; Franklin and Holding, 1977; Rubin, Wetzler and Nebes, 1986; Zola-Morgan, Cohen and Squire, 1983). In studies without cue words, Fitzgerald (1988) found 
a tendency to remember events that occurred during the transition phase when subjects (aged 62-75 years) were simply asked to report on three vivid memories that came to mind, and Fromholt and Larsen (1991) replicated this transition phase concentration when they asked elderly subjects (aged 71-89 years) to provide a 15-minute free narrative report on their important life events. The transition phase effect has also been discovered in the recall of public rather than personal events. Survey respondents, representing all adult ages, and who live in diverse areas such as the United States and Lithuania, when asked to report on the two most important national or world events or changes that have occurred in the last 50 years, tend to report events that fall within the transition phase (Schuman, Rieger and Gaidys, 1994; Schuman and Scott, 1989).

Rubin et al. (1986) sought to explain the transition phase effect by an appeal to a differential sampling hypothesis. According to this hypothesis, the transition phase is particularly rich for reminiscing about one's past, perhaps because the transition phase is most important with respect to the formation of one's identity in comparison to other phases of the lifespan (see also Fitzgerald, 1988). In memory tasks that emphasize reviving autobiographical experience, focusing on one's "life story" would encourage the retrieval of those experiences that are formative, since without them, the thematic aspects of such a narrative would not be compelling (Robinson and Hawpe, 1986). Support for this view partly comes from noting that when the tasks do not necessarily require the revival of personal experiences, such as those studies (Fitzgerald, 1988; Fromholt and Larsen, 1991) that ask only for vivid or important memories, what is recalled overwhelmingly tends to be personal rather than public events. Personal events are more descriptive of oneself than public ones. Moreover, even when the task requires the recall of public events (e.g. Schuman and Scott, 1989), these events are often seen as important with respect to their personal relevance. As an example, World War II was often mentioned because of particular personal experiences associated with the war (e.g. being injured). Public events then, are often seen as associated with personal experience, perhaps because, as suggested by Neisser $(1982,1988)$ with respect to "flashbulb" memories," they can serve as a means to associate one's own life history with History writ large. Indeed, Schuman and Scott (1989) report that flashbulb memories of the Kennedy assassination came especially from those in their transition phase at the time the assassination took place.

An important point to emphasize about the differential sampling hypothesis is that no role is assigned to the possibility that events that occur during the transition phase are actually known better than events that occur during other phases of the lifespan (Rubin et al., 1986), with the exception of infantile amnesia. That is, according to the hypothesis, events are seen as being encoded equally well, and the same rate of forgetting is seen to be maintained, throughout the lifespan. The transition effect then, is solely attributed to a bias in the sampling of memories during retrieval. The survey data may best illustrate this point. Consider someone who experienced WWII during the transition phase, and who also reported WWII but not the Vietnam War on the survey as one of two most important events that had occurred during the last 50 years. Would this necessarily mean that such an individual failed to encode Vietnam as thoroughly as WWII, or retained a memory of Vietnam less well than a memory for WWII? Of course not. In fact, if directly asked about Vietnam such an individual might have quite good knowledge of the 
event. According to the differential sampling hypothesis, the person only had a bias to select WWII over Vietnam because WWII was more easily reminisced.

However, evidence that the Vietnam War is better known by those who had experienced it during the transition phase has been recently provided by Schuman et al. (1997). In this study, survey respondents were asked directly to say what the Tet Offensive was and also what the village of Mylai referred to. Both events occurred during the Vietnam War, the former in 1968 and the latter in 1969. The authors found that survey respondents who experienced the Vietnam War during their transition phase demonstrated greater knowledge of the specific events in comparison with those individuals who were younger than the transition phase (or not alive at that point) when these events occurred, and more importantly, greater knowledge than those individuals who were older than their transition phase when the Vietnam War occurred. A similar transition effect was found for WPA, Marshall Plan, Joe McCarthy, and Woodstock, although no transition effect was found for direct questions about Watergate, John Dean, or Christa McAuliffe. Rubin (1995) also found that people have greater knowledge and memory for events that occur during the transition phase.

Unlike the other transition phase effects, these results of Schuman et al. (1997) and Rubin (1995) cannot be explained by an appeal to the differential sampling hypothesis. According to the differential sampling hypothesis, people who are older than the transition phase should know (i.e. encoded and retained) events such as the Vietnam War as well as those individuals who experienced the Vietnam War during the transition phase. When asked direct questions about certain events of the war, which serve to sample these events from others that would be stored in memory, differential sampling no longer applies. Thus, the hypothesis would predict an equal ability to remember these events regardless of whether they occurred during or after the transition phase. The transition effect found by Schuman et al. (1997) suggests that other memory factors besides retrieval and sampling, such as encoding and retention factors, also have a role in the effect.

Since the data collected by Schuman et al. (1997) consist of reports of verifiable public events, they are unique in transition effect studies by providing an opportunity to also examine the errors in people's autobiographical reports. Most of the other data revealing a transition effect consist of reports of unverifiable personal experiences. Thus, there is considerable uncertainty regarding the extent to which these reports are accurate or fraught with error. As in John Dean's case, these remembrances may include a certain degree of confabulation (Neisser, 1981). In this paper, we will report analyses of errors that will illustrate, among other things, that the transition phase is also a major contributor to error-prone reporting.

In an initial limited analysis of errors, Schuman et al. (1997) found that individuals who experienced the Korean War during their transition phase were more likely to report the Tet Offensive as having occurred during the Korean War than did other individuals. For this cohort the Korean War apparently serves as a transition phase experience that can overshadow the ability to remember Vietnam War events. In other words, transition phase experiences have the capacity to proactively interfere with the remembering of later similar events. This paper provides a fuller and more systematic analysis of respondent errors, which reveal other examples of these transition phase effects. 
Our analyses of errors extends understanding regarding the processes involved in remembering across the lifespan. We show that errors in the attempt to remember past events involving the use of both semantic and lexical memory systems, can result from proactive and possibly from retroactive interference, and reveal age trends in which certain types of errors are more likely in particular cohorts.

\section{Method}

\section{Respondents}

All respondents were 18 years of age and older and were interviewed in one of two standard surveys. First, the Detroit Area Study was conducted in 1991 (DAS-91) through face-to-face interviews of a probability sample of adults, drawn from the Detroit Metropolitan area. DAS-91 had a 78.1\% response rate and a final sample size of 1042 individuals. Second, as part of a national telephone survey conducted through random-digit dialing, the University of Michigan's Survey Research Center interviewed a cross-section of approximately 500 adults during each of 5 consecutive months in 1993 (SRC-93). The sample for each month of the SRC93 consisted of approximately 300 new cases, and 200 individuals who had been interviewed 6 months earlier (but not with the questions reported in this paper). There was a $69.6 \%$ response rate for the new respondents over the 5 months of interviewing with SRC-93. As probability samples, both surveys had a full range of American adults in terms of age, sex, and other demographic factors, though the Detroit survey had a higher percentage of black respondents and, of course, did not represent the different regions of the country as did the national survey. However, in Schuman et al. (1997) it is evident that the two surveys produced comparable results except where racial issues were concerned.

\section{Procedure}

Mid-way in the interviews in both surveys, respondents were told: This next section concerns a few words and names from the past that come up now and then, but that many people have forgotten. Could you tell me which ones you have heard of at all, and, if you have, what they refer to in just a few words?

Respondents participating inDAS-91 wereeach givennineitems thatrepresented distinct events that happened as long ago as a U.S. government sponsored work program of the 1930s (the "WPA"), and as recently as the 1986 explosion of the Challenger space-shuttle ("Christa McAuliffe"). The other seven items were the Holocaust, the Marshall Plan (the U.S. government plan for the economic reconstruction of Germany following WWII), Joe McCarthy (a U.S. Senator of the 1950s who accused many prominent individuals of being communists), Rosa Parks (a black women, who, in the 1950s, protested segregation in Montgomery, Alabama, by refusing to move to the back of a bus), the Tet Offensive (the Vietnam War offensive by North Vietnamese troops against American forces), Woodstock (the 1969 outdoor rock concert that was a high point of the 1960s countercultural movement), and Watergate (the symbol of a series of events that led to the resignation of Richard Nixon from the U.S. Presidency). The SRC-93 survey 
asked each respondent two to four items, with a total of four items being asked overall. Two of these four items (Tet Offensive and Woodstock) were replications of items asked earlier in DAS-91, and two were new items: the village of Mylai (the Vietnamese village that was the scene of atrocities carried out by American troops) and John Dean (a key figure in the Watergate scandal). Thus, altogether, there was a total of 11 different items, as well as a replication of two of these. In both surveys, additional questions obtained information about the respondents' age and other demographic variables.

Table 1 gives the number of respondents asked each of the 11 items, the survey used, and the approximate date of occurrence for each event. The number of respondents asked each item in the SRC-93 surveys varies (from 1,008 to 2,001) because for most months a subset of the 4 items were asked.

\section{Results and Discussion}

Respondent reports were coded as correct, partly correct, or wrong (including don't know responses) in analyses reported by Schuman et al. (1997). For the analyses presented here, correct and partly correct responses were combined and simply considered as correct. In addition, the initially coded wrong responses were recoded as being either don't know responses (DKs) or substantive errors. The recoding scheme did not affect the pattern of findings originally reported by Schuman et al., and facilitated comparability among correct responses, substantive error responses, and DKs, since all types of responses were made to assume the same range of values (occurrence or non-occurrence). For each of the items, Table 1 presents the proportion of correct, error and DKs, following the recoding scheme.

In comparing substantive errors with DKs, the proportion of errors tends to be rather low and ranges from $1.3 \%$ to $12.9 \%$, whereas the DKs are much more frequent ranging from $9.7 \%$ to $73.3 \%$. The much greater frequency of DKs is probably the result of question wording that encourages DKs: respondents were first asked

Table 1. Distribution of types of responses

\begin{tabular}{lrrrrrr}
\hline Item & Survey & Valid $N$ & Date of event & \% Correct & \% DKs & \% Errors \\
\hline WPA & DAS-91 & 1033 & 1938 & 37.0 & 61.5 & 1.5 \\
Holocaust & DAS-91 & 1032 & 1945 & 76.1 & 18.5 & 5.4 \\
Marshall Plan & DAS-91 & 1033 & 1947 & 20.6 & 73.3 & 6.1 \\
Joe McCarthy & DAS-91 & 1032 & 1954 & 35.8 & 51.4 & 12.9 \\
Rosa Parks & DAS-91 & 1033 & 1955 & 78.9 & 16.9 & 4.1 \\
Tet Offensive & SRC-93 & 2000 & 1968 & 33.5 & 61.6 & 5.0 \\
Tet Offensive & DAS-91 & 1032 & 1968 & 28.7 & 67.4 & 3.9 \\
Village of Mylai & SRC-93 & 1008 & 1969 & 35.4 & 63.1 & 1.5 \\
Woodstock & SRC-93 & 2001 & 1969 & 74.3 & 21.2 & 4.4 \\
Woodstock & DAS-91 & 1033 & 1969 & 73.1 & 21.8 & 5.1 \\
John Dean & SRC-93 & 1511 & 1973 & 32.6 & 57.2 & 10.3 \\
Watergate & DAS-91 & 1033 & 1973 & 85.3 & 9.7 & 5.0 \\
Christa McAuliffe & DAS-91 & 1033 & 1986 & 50.6 & 48.1 & 1.3 \\
Mean percent & & & & 50.9 & 44.0 & 5.1 \\
\hline
\end{tabular}


whether they heard of the words or names before providing a substantive response. In opinion research, the technique of asking respondents first if they are familiar with an issue before providing an opinion is known as providing a DK filter, and has been shown to increase DKs in comparison to opinion questions in which a DK filter is not used (Bishop, Tuchfarber, and Oldendick, 1986; Schuman and Presser, 1981).With our items, the DK filter was apparently effective in discouraging respondents from providing a substantive response when they felt that there was a lack of familiarity with an item, though it is also likely that admissions of ignorance occur much more readily with knowledge questions than with opinion questions.

That error responses reflected attempts by respondents to provide a correct response was indicated by an examination of answers to DAS-91, in which all respondents were presented with nine items. We were concerned that errors could have been made primarily by a tiny subset of respondents who simply were willing to guess wildly. If this were true, then there should be an identifiable set of respondents who provided errors to many items and who also did not provide correct responses to the remaining items. No such pattern emerged. Over one-third $(35.3 \%, N=365)$ of the DAS-91 respondents provided errors. Further, the majority of the respondents who provided errors had only a single error, and only one respondent made as many as four errors (and this person also provided two correct responses). More generally, respondents who provided errors also tended to provide correct responses to other items. Only eight respondents who provided errors did not have any items correct, and of these, seven respondents had just one error and the remaining person had two errors. Thus, the data revealed that, in general, when people were responding with errors they were doing so with an attempt to provide a correct response.

\section{Types of errors}

In reviewing the substantive errors, we developed a coding scheme that categorized errors within three independent classification systems: basic, time and name errors. All errors were assessed within each classification system.

\section{(1) Basic errors}

For basic errors, we developed a coding scheme that differentiated the content of responses into six mutually exclusive types: quasi-correct, related event, loose association, inversion, vague, and uninterpretable. The coding operation consisted of two phases. In the first phase, the first two authors, working together, coded error responses to Joe McCarthy, Rosa Parks, John Dean, and Watergate. During this first phase, we were able to determine the kinds of basic codes and the criteria by which responses could be assigned to them. In the second phase, the first two authors independently coded responses to Woodstock (DAS-91 and SRC-93), Tet Offensive (DAS-91 and SRC-93), Mylai, Holocaust, WPA, Marshall Plan, and Christa McAuliffe, and reached an agreement level of $77.4 \%$. Discrepancies were resolved through discussion.

The basic errors coding scheme and criteria are as follows:

(a) Quasi-correct errors were not actually wrong on the part of the respondents, but indicated the restricted version of the investigators initially as to what should be a correct response. For example, we assumed that the only possible correct answer to Joe McCarthy would be to refer to the Wisconsin Senator who gained 
notoriety for his pursuit of communists. Yet in retrospect it is clear that responses referring to a "New York Yankees manager" should be considered legitimate.

(b) Related event errors referred to an event that was conceptually or semantically related to the target event, by belonging to the same general category, but which were nevertheless clearly incorrect (e.g. identifying an event from the Vietnam War as part of the Korean War).

(c) Loose association errors were those that used some word or phrase in the question (such as the last name of the cued individual or the word "offense" in "Tet Offensive") to construct a response, though a response that was incorrect. If a response could be categorized as either a related event or loose association, the response was considered a loose association. As a notable example, some errors to John Dean referred to a "secretary of state," whom we infer was Dean Rusk. Since Dean Rusk is conceptually related to John Dean in that both figures had

Table 2. Examples of basic error responses

\begin{tabular}{|c|c|}
\hline $\begin{array}{l}\text { Error/ } \\
\text { Item } \\
\end{array}$ & Response \\
\hline \multicolumn{2}{|l|}{ Quasi-correct/ } \\
\hline Holocaust & The atomic bomb on Japan \\
\hline Joe McCarthy & Manager of New York Yankees \\
\hline Rosa Parks & Changed 12th to Rosa Parks \\
\hline Woodstock & Charlie Brown's bird \\
\hline \multicolumn{2}{|l|}{ Related event/ } \\
\hline Marshall Plan & Divided up Berlin and all the goodies after WWII \\
\hline Tet Offensive & During the Korean War the last charge to win the war \\
\hline Village of Mylai & A Korean village \\
\hline Woodstock & Peace protest \\
\hline \multicolumn{2}{|l|}{ Loose association/ } \\
\hline WPA & World Peace Association \\
\hline Joe McCarthy & WWII, “we shall return” \\
\hline John Dean & Movie star killed in an automobile accident \\
\hline Christa McAuliffe & A tennis player \\
\hline Tet Offensive & $\begin{array}{l}\text { The line in football where you have } 3 \text { backs and you split a } \\
\text { wide receiver off to the right. A handoff to the running back }\end{array}$ \\
\hline \multicolumn{2}{|l|}{ Inversion/ } \\
\hline Joe McCarthy & They thought he was a communist but it was never proven \\
\hline Rosa Parks & Gave up her seat on the bus \\
\hline Tet Offensive & A major offensive when they started using B52 bombers \\
\hline Watergate & The break-in to recover tapes \\
\hline \multicolumn{2}{|l|}{ Vague/ } \\
\hline Holocaust & What a hell \\
\hline Joe McCarthy & Political figure \\
\hline Rosa Parks & A black woman \\
\hline Watergate & Scandal \\
\hline \multicolumn{2}{|l|}{ Uninterpretable/ } \\
\hline WPA & Should have never existed. Ridiculous \\
\hline Holocaust & I hated the burning \\
\hline Tet Offensive & Preacher in the pulpit, sinners \\
\hline Woodstock & A name brand for a canned food \\
\hline
\end{tabular}


been administration officials, these errors could have been appropriately coded as related events. Yet, given that the word Dean also motivated respondents to think of Dean Rusk, it was decided to code these errors as loose associations. Similar thinking led to those who referred to a 1960s Presidential candidate to the item Joe McCarthy (i.e., Eugene McCarthy) to be coded as loose associations.

(d) Inversion errors are particularly interesting in that respondents inverted the subject and object of the event. For example, there were responses that claimed Rosa Parks gave up her seat on a bus, the opposite of what actually happened, and that Joe McCarthy was known for having been accused of being a communist!

(e) Vague errors were those that may have referred to the target or quasi-correct event, but respondents did not provide enough information to determine accuracy (e.g. responding simply with the word "scandal" to Watergate).

(f) Uninterpretable errors were those errors whose referent we were not able to determine.

Table 2 provides examples of actual error responses that we observed and how these responses were coded. For some of these responses and codes, further explanation will be helpful. With regard to quasi-correct responses, Rosa Parks was a DAS-91 item, and responses of "12th" referred to the name of a Detroit street that was changed to honor Rosa Parks, a Detroit resident. In the loose associations, one of our more amusing responses was this detailed description of an offensive football play, which was apparently provided with a great deal of conviction! Regarding inversions, the Tet Offensive was actually an offensive by the North Vietnamese against American troops, but the reverse was often what was recalled. Finally, we coded responses as uninterpretable if, with our limited knowledge, we could not fathom a referent for the response: for example, it would not be a surprise if some informed readers were able to confirm that Woodstock is a brand name of a canned food (although there was only one such response).

Table 3 presents the relative frequencies of occurrence of the different basic errors for each item. Most striking is that related events and loose associations were the most common type of errors, in combination accounting for over half of all errors. The predominance of these error types is probably an indication of the reliance that respondents have on using semantic and lexical memory systems, respectively. Also notable is that both Tables 2 and 3 reveal that each kind of basic error was not unique to any one item: for example, inversion errors occurred with four different items (Joe McCarthy, Rosa Parks, Tet Offensive, and Watergate). The discovery of inversion errors has been one of the unique contributions of our analyses.

(2) Time errors

There were instances in which people reported events that, in addition to receiving basic codes, clearly indicated a reference to an event that occurred either earlier or later in time than the target event. Thus, the codes earlier time and later time were used to refer to responses that were mistakenly associated with earlier or later historical times, respectively. For example, one subject responded to the Watergate item by mentioning a big scandal over a bridge, we inferred that this response referred to Ted Kennedy and the Chappaquiddick accident, which occurred earlier in time than the Watergate scandal.

Table 4 provides the distribution of time errors. Overall, approximately onefifth of all errors involved either an earlier or later time displacement, and for some 


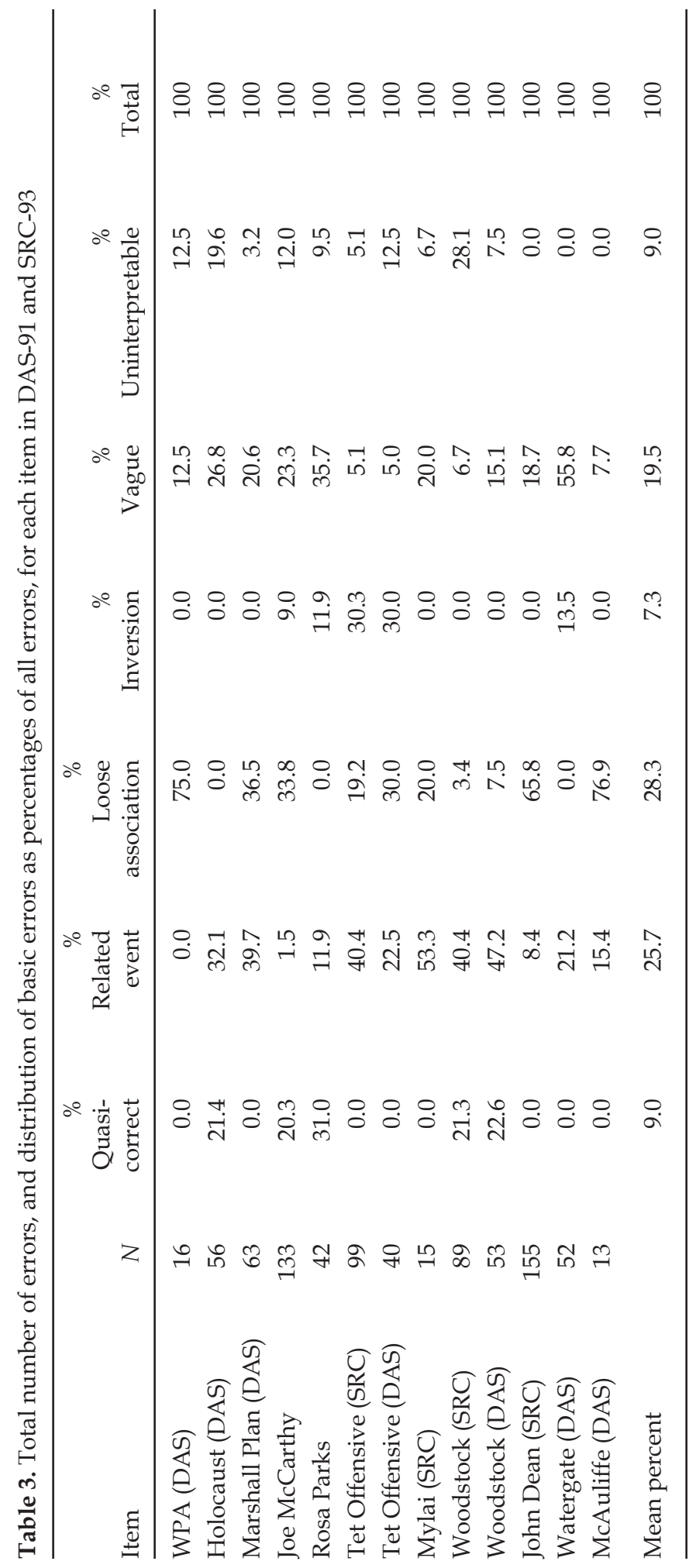


Table 4. Total number of errors, and distribution of time errors as percentages of all errors, for each item in DAS-91 and SRC-93

\begin{tabular}{lrrrr}
\hline Item & $N$ & \% Earlier time & \% Later time & \% Total time \\
\hline WPA (DAS) & 16 & 0.0 & 0.0 & 0.0 \\
Holocaust (DAS) & 56 & 0.0 & 0.2 & 0.2 \\
Marshall Plan (DAS) & 63 & 9.5 & 12.7 & 22.2 \\
Joe McCarthy (DAS) & 133 & 15.8 & 36.8 & 52.6 \\
Rosa Parks (DAS) & 42 & 4.8 & 35.7 & 40.5 \\
Tet Offensive (SRC) & 99 & 29.3 & 4.0 & 33.3 \\
Tet Offensive (DAS) & 40 & 25.0 & 0.0 & 25.0 \\
Mylai (SRC) & 15 & 26.6 & 0.0 & 26.6 \\
Woodstock (SRC) & 89 & 3.4 & 2.2 & 5.6 \\
Woodstock (DAS) & 53 & 0.0 & 0.0 & 0.0 \\
John Dean (SRC) & 155 & 43.2 & 7.1 & 50.3 \\
Watergate (DAS) & 52 & 3.8 & 9.6 & 13.5 \\
McAuliffe (DAS) & 13 & 15.4 & 0.0 & 15.4 \\
Mean percent & & 13.6 & 8.3 & 21.9 \\
\hline
\end{tabular}

of the items that involved names of individuals (e.g. Joe McCarthy, John Dean and Rosa Parks) nearly half of the errors could be coded also as time errors. It is notable that no single factor can account for the dominance of time errors within these items. Time errors were observed with three kinds of basic errors, quasi-correct, related event, and loose association errors, ${ }^{1}$ and as seen in Table 3 , the proportion of respondents committing these basic errors differed depending on the item. Each item, then, invites processes that are unique to it. There is an observable tendency, shown in Table 4, for older events (e.g. Joe McCarthy, Rosa Parks) to promote later time errors and for more recent events (Tet Offensive, village of Mylai, John Dean) to promote earlier time errors. This is due simply to the fact that for older target events most of our respondents experienced a greater number of subsequent events in comparison to events that had occurred even earlier than these older target events, and for more recent target events, most respondents experienced other events that had happened longer ago than events that had happened even more recently than these recent target events.

\section{(3) Name errors}

Some errors were clearly in reference to a particular individual or event that we could confidently name. Table 5 presents the name errors that we found, and how they were cross-referenced with basic and time errors. To the DAS-91 item Joe McCarthy, we received five responses that referred to a New York Yankees baseball manager during the 1930s and 1940s (Yankee Manager), to a U.S. Army General who served both during WWII and the Korean conflict ( $N=15$; Douglas MacArthur), to a 1968 Presidential candidate ( $N=6$; Eugene McCarthy) and a musician associated with the 1960s band the Beatles ( $N=2$; Paul McCartney), which we collapsed for purposes of age-trend analyses (see below) into the name

1 By their nature, inversion, vague, and uninterpretable errors are not open for time errors. Inversion errors refer to the target event, and vague and uninterpretable responses would not clearly indicate referring to a particular point in time. 
Table 5. Name errors cross-referenced with basic errors and time errors in DAS-91 and SRC-93

\begin{tabular}{lll}
\hline $\begin{array}{l}\text { Item/ } \\
\text { Name error }\end{array}$ & Basic error & Time error \\
\hline Joe McCarthy (DAS)/ & & \\
Yankee Manager & Quasi-correct & Earlier time \\
Douglas MacArthur & Loose association & Earlier time \\
Sixties & Loose association & Later time \\
J.P. McCarthy & Quasi-correct & Later time \\
Jack McCarthy & Loose association & Later time \\
Tet Offensive (SRC and DAS) & Related event & Earlier time \\
World War II & Related event & Earlier time \\
Korean War & & \\
Village of Mylai (SRC) & Related event & Earlier time \\
World War II & Related event & Earlier time \\
Korean War & & \\
John Dean (SRC) & Loose association & Earlier time \\
Dean Rusk & Loose association & Earlier time \\
James Dean & Loose association & None \\
Jimmy Dean & Loose association & None \\
James/Jimmy confusion & & \\
\hline
\end{tabular}

error Sixties, to a Detroit area radio-host $(N=22 ; J . P$. McCarthy $)$, and finally, to a Detroit-area television news anchor $(N=16$; Jack McCarthy). To the SRC-93 item Tet Offensive we received 8 error responses that referred to WWII and 18 Korean War responses; the DAS-91 Tet Offensive item mirrored this pattern with 3 WWII and 5 Korea responses. The SRC-93 village of Mylai item also received 1 WWII and 3 Korea errors. Finally, to the SRC-93 item John Dean, we received 14 responses about a Secretary of State (at times including reference to the Kennedy administration), which we primarily coded as Dean Rusk (but we are also aware of Dean Acheson); there were 49 responses to a 1950s movie actor who was killed in an automobile accident (James Dean), 14 responses referred to a singer who is also known for sausage advertisements (Jimmy Dean), and 9 responses that blended elements of James and Jimmy Dean (James/Jimmy confusion).

In the majority of cases, for those name errors that were cross-referenced as loose association errors, the respondents failed to explicitly recognize that they were referring to someone who had a first (and even last) name other than the presented item. For example, we received many responses to Joe McCarthy ("he ran for President in the 60s") and John Dean ("he was a movie star killed in automobile accident") that were simply descriptive of an unnamed though identifiable (and incorrect) individual. In other cases, respondents did recognize the name of the mistaken individual, but only after substantive comments that indicated that an error had already been made (e.g. "he was Secretary ... of State under ... Kennedy, ... that was Dean Rusk"). These responses illustrate that the presentation of items cued respondents to gain access to associated information in lexical (and/or semantic) memory, but that the activated information, although containing relevant content, was nevertheless lacking in the critical ability to identify correctly what was being retrieved. 
Age-trends

As reported by Schuman et al. (1997), there were distinct age-trends in the correct responses of 7 of the 11 different items that were presented to respondents in DAS-91 and SRC-93. For example, those correctly identifying the WPA as a 1930s government program to provide employment during the Great Depression had a modal age of 70-74 in the 1991 survey, which meant that they had been 17-21 in 1938 at the height of the program. Furthermore, the overall age-trend for knowledge of the WPA was essentially monotonic, with decreasing knowledge at younger ages in 1991. On the other hand, those most knowledgeable about the Tet Offensive were 45-49 in the 1993 national survey, which placed them in their early 20s when the Offensive occurred. Moreover, in this case the overall association of age to knowledge was curvilinear, with less knowledge shown both by those who were younger and by those who were older than the 45- to 49-year-old cohort in 1993. (See Schuman et al., 1997, for results for other events, including some exceptions to the general agetrends, as well as effects due to other variables, such as sex.)

In our present analysis of errors in remembering, we had two goals. First, there was the desire to determine whether there were age-trends, and whether these age- trends corresponded to the transition phase, as much had been revealed with the correct responses. Second, in order to gain greater insight into these age-trends, analyses were conducted to determine whether the ages of those respondents who produced errors were either less or more than those who produced correct responses. The first goal was accomplished by examining all basic, time and name error responses that had five or more cases with linear and quadratic logistic regression models. For each error, a dichotomous dependent variable was constructed based on the presence of the error or the presence of any other response, be it another error, a DK or a correct response. For example, in assessing whether an age-trend was present with inversion errors to the SRC-93 Tet Offensive item, the presence of an inversion error received one value in the dichotomous variable and any other response to the Tet Offensive, whether it be a non-inversion error, a DK, or a correct response was assigned the other value. In each of the linear models, age of respondent was entered as a predictor variable to test whether either younger or older respondents were more likely to produce each error. In the quadratic models, both age and the square of age were entered as predictor variables to examine whether a curvilinear trend was present, and whether the error was more often produced by respondents within a particular age range. With all of the linear and quadratic models, education of respondent, a variable that consisted of six categories based on years of education, was included as a control variable.

The second goal was accomplished by focusing on those errors that revealed significant age-trends, and contrasting each of these error responses against only correct responses using linear logistic regression models, again including education as a control variable. ${ }^{2}$ One possibility is that although an error may show a significant age-trend, the ages that commit the error may not be different

2 Note that the regressions in the body of Tables 6 and 7 compare the ages of those making a particular type of error (e.g. inversion for the Tet Offensive) who score 1, with all other responses to that item (i.e. to the combination of correct answers, Don't Know responses, and other types of errors) who score 0 . However, the regressions referred to here (and in notes to Tables 6 and 7) involve a particular type of error in comparison to correct responses only. 
from those who respond correctly. Such a pattern could occur, for example, when the same original experience was being reported incorrectly by some respondents but correctly by others. On the other hand, another possibility is that the ages of those respondents that commit the error differ significantly from those who are correct. This pattern could result from different original experiences, occurring at different times, one motivating the error and the other a correct response, or could result from the same original experience affecting respondents of different ages in different ways.

Tables 6 and 7 present the results of both sets of analyses. Table 6 shows those errors that produced significant regression coefficients for age and/or the square of age with the SRC-93 data, and Table 7 shows the significant results for DAS-91. As can be seen, 15 errors from 7 items revealed significant agetrends, and 2 items, Dean (SRC-93) and McCarthy (DAS-91), account for 8 of these errors. Negative beta- weight values in the linear models indicate that younger respondents more often produced the error, whereas positive values point to older people. The negative beta- weights in the square of age terms in the quadratic model indicate a curvilinear trend in which respondents who were middle-aged when surveyed were more likely to produce the indicated errors.

Of primary interest are those respondent ages that correspond to producing particular errors. In order to gain a sense of these ages, the modal age ranges of the respondents who produced each significant error were computed at the time the target item event occurred, and at the time of those errors that indicated a datable event other than the target event (Korea, Rusk, Sixties and Yankee). ${ }^{3}$ Whether these modal ages differed significantly from correct responses are also reported in notes to Tables 6 and 7 . The striking feature of those items that yielded significant age trends is that most of them $(11 / 15,73 \%)$ have modal ages that implicate the transition phase in promoting the erroneous response (Tet/Inversion, Tet/Korea, Woodstock/ Related, John Dean/Rusk, Marshall/Vague, Marshall/Related, Joe McCarthy/ Later, Joe McCarthy/Yankee, Joe McCarthy/Vague, Joe McCarthy/ Inversion, Watergate/Related).

The errors to the Tet Offensive (see Table 6) are most instructive with respect to illustrating the role of the transition phase in promoting wrong responses. Importantly, the inversion errors are committed by respondents significantly younger than those who responded correctly $(B=-0.053, p<0.01)$, and the Korea

3 The computation of modal age range is based on 12 class intervals for the ages of respondents, with each class interval except for the first (18-24) and the last (75+), encompassing 5 years (e.g. 40-44, 45-49). The logic of this statistic is based on the fact that if each class interval consisted of respondents who had an equal tendency to respond with a particular error, any three class intervals would contain $25 \%$ of these error responses, and any four class intervals would contain $33 \%$ of these error responses. Thus, if three adjacent class intervals (representing a span of 15 years) provide $33 \%$ of the responses, the respondents with those ages provide relatively more of that particular type of error response than respondents of other ages. Thus, the modal age range is computed from the fewest number of those class intervals (up to a maximum of three) that contain at least 33\% of the proportional responses. By using proportions of frequencies within each class interval, the statistic corrects for unequal interval sizes. When the modal age range consists of fewer (than three) class intervals, a greater bunching of responses within certain ages is indicated than when the modal age range involves three class intervals. In addition, the $33 \%$ "rule" allows an objective means of defining whether a distribution is bimodal. If two non-continuous sections of a distribution contain three class intervals that accounted for at least $33 \%$ of the proportional responses, the distribution was considered as bimodal. Modal ranges were then computed for both sections of the distribution. 


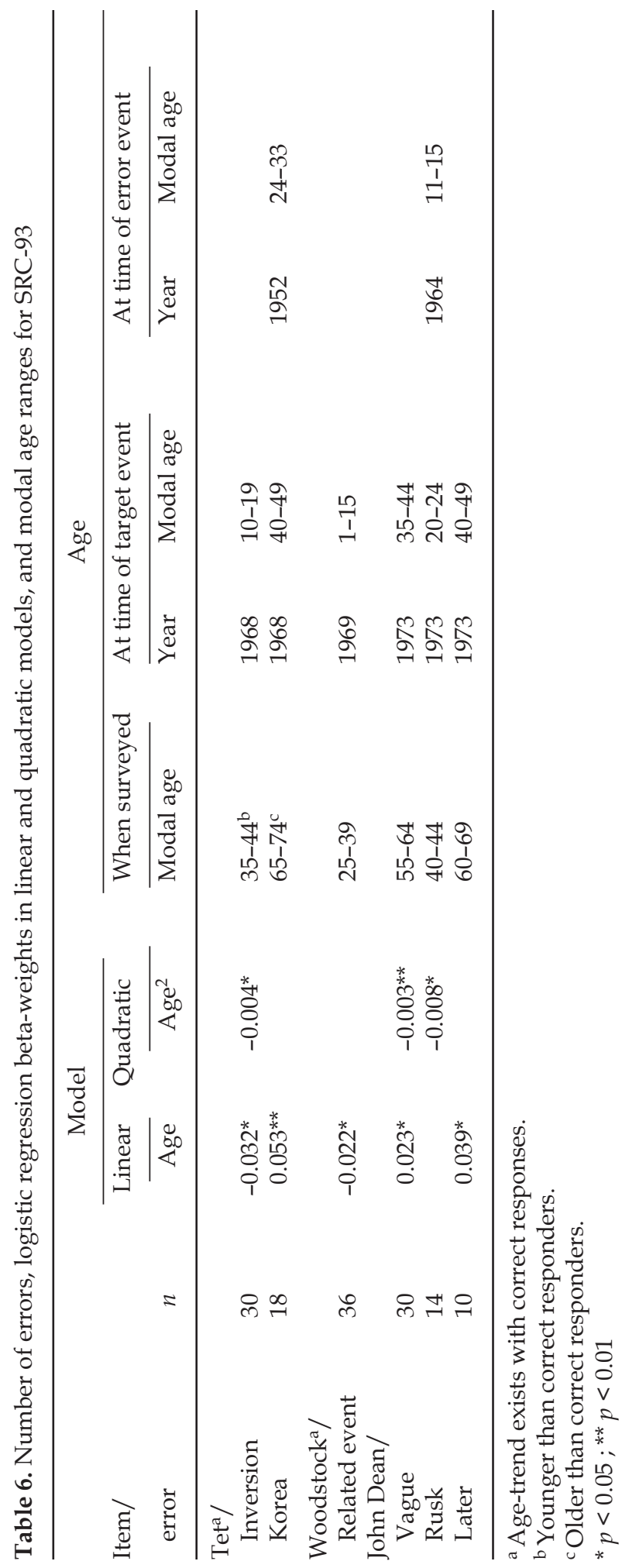




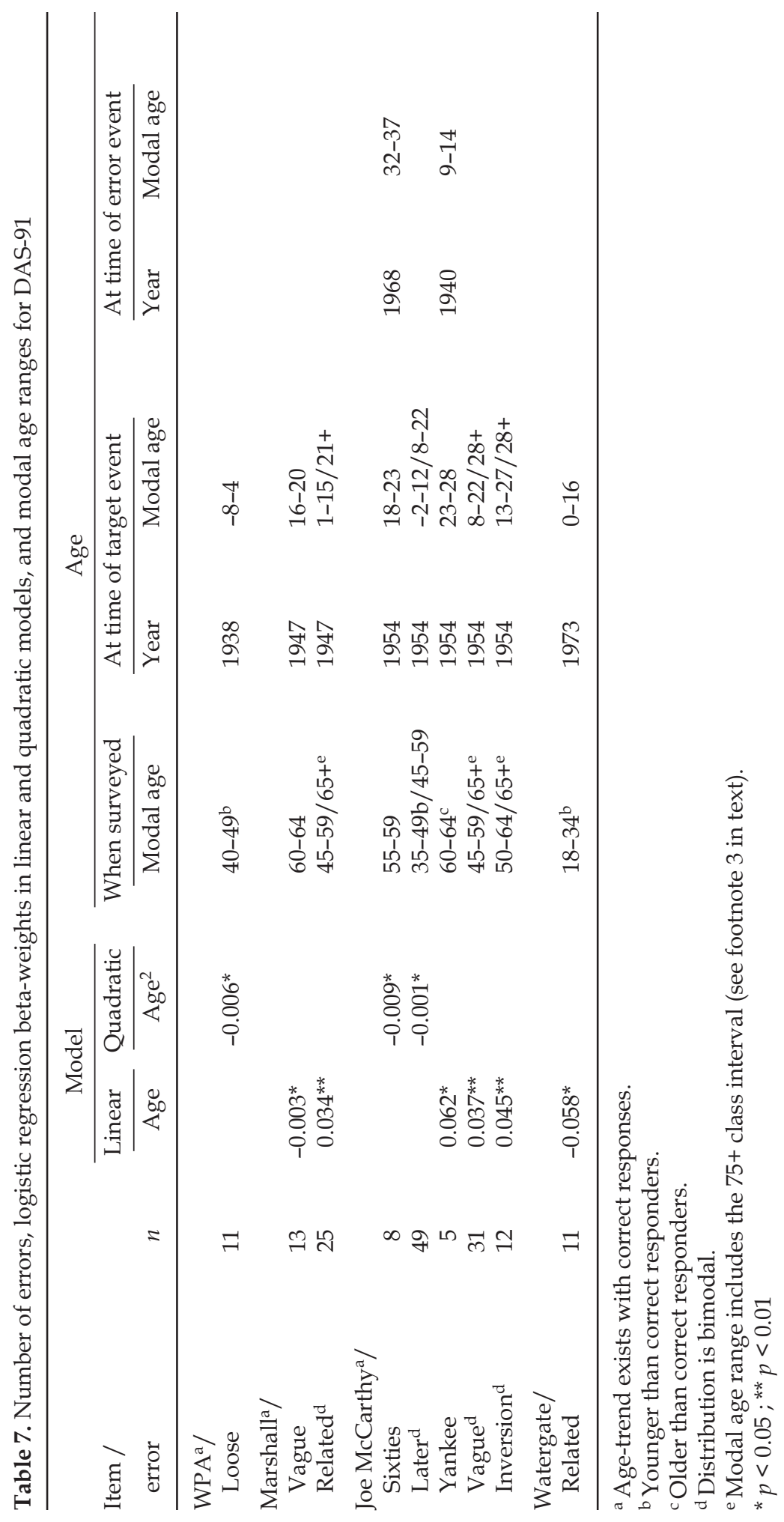


errors are committed by those significantly older $(B=0.065, p<0.001) .{ }^{4}$ Whereas the inversion errors suggest that the same experience affected younger respondents differently than those who were correct, the Korea errors suggest that older respondents had a different experience in mind than those who were correct.

Focusing on the inversion errors and that the transition phase is implicated in inversion errors to Joe McCarthy as well (see Table 7), the nature of this type of error suggests that although the transition phase may have promoted the remembering of the elements of these experiences, there is no guarantee that individuals will reconstruct the events with the correct relationship. However, that the Tet Offensive inversion errors are provided by respondents who were of younger ages during the transition phase when the event occurred in comparison to those respondents who were correct, whereas respondents who provided inversion and correct responses to Joe McCarthy represent the same transition phase ages as those who were correct, suggests that the inversion errors to these two items are not alike. One difference is that the inversion errors for Tet Offensive seem to be possibly motivated by an overall schematic theme (that the United States is a militarily powerful nation), whereas there is no apparent schematic theme for inversion errors to Joe McCarthy. ${ }^{5}$ The schematic characterization of the Tet Offensive inversion errors, which were committed by respondents who experienced the Tet Offensive while at early transition phase ages, is evidence that supports the hypothesis that early adolescence is particularly marked by developing expectations concerning what characterizes entities in the world (Duncan and Agronick, 1995; Stewart and Healy, 1989).

The Watergate (see Table 7) and Woodstock (see Table 6) -related event errors are also supportive of this early adolescence hypothesis in that they are reflective of the use of a schematic theme to confabulate a response, and were provided by persons who are at younger ages within the transition phase (the Watergate errors are from significantly younger ages than correct responses, $B=-0.072, p<0.01$, and the Woodstock errors are directionally from younger respondents, but not significantly so, $B=-0.017, p=0.16$ ). The Watergate-related event errors appear to have used the general theme of government scandal to refer to some scandal that occurred either earlier ("Kennedy involved in some crime") or later ("Big scandal in government, Reagan's term") than Watergate, or to construct an event

4 Although Table 6 shows a modal age range that indicates that the respondents were at the older ages of the transition phase, or even older than the transition phase when experiencing Korea War events, this modal range fails to adequately represent the $17 \%$ of Korea War respondents between the ages of 14 and 18 years in 1952. Korea War responses to DAS-91 Tet Offensive also suggest a transition phase effect. They are consistent with those of SRC-93 in approaching significance with the curvilinear trend, with the square of age $B=-0.01, \mathrm{p}=0.09$. Also, at the time of survey, the modal age range is $50-54$ years, which corresponds to an age in 1952 of 11-16 years. There were only three Korea War responses to the village of Mylai item in SRC-93, which were too few to analyze with the regression models.

5 The view that inversion errors can often be motivated by schematic reconstruction receives support from the five inversion errors to Rosa Parks, although these errors are not related to the transition phase. The inversion errors were always committed by whites, and by individuals who appeared older in comparison to the other respondents who had also made substantive errors to the Rosa Parks item $(B=0.060, p=0.07)$. A reasonable interpretation is that individuals who are reporting these inversions are affected by a schematic impression of history that emphasizes blacks as being submissive to whites. For black respondents, the unusual nature of Rosa Park's actions are remembered. For whites, and particularly for those who are older and in which submissiveness was more likely to be a socialized norm, the importance of the details are susceptible to being dominated by a schematic memory. 
that apparently never happened at all ("Bugging the Pentagon, Nixon and his staff"); with Woodstock, the errors can be generally characterized as being based on overall themes of the 1960s, such as the peace movement (e.g. "demonstration against Vietnam") or civil rights (e.g. "more freedom, women's rights").

The Korea errors to the Tet Offensive are noteworthy in that error-laden earlier transition phase events were remembered instead of cued related events that occurred later in time. The Rusk errors to John Dean (see Table 6) are also consistent with this pattern, except that those committing the Rusk errors experienced both Dean Rusk and John Dean during their transition phase. Both errors indicate the presence of proactive interference if these respondents also have (or once had) correct knowledge about the Tet Offensive and John Dean. Since the errors were conceptually related to the target events, the claim that the respondents do (or did) know about the target events is quite plausible; retrieval attempts guided the respondents to relevant semantic categories in memory (i.e. Asian War, Administration Official) that would probably exist only if the target events also reside (or once resided) in memory. In the case of Dean Rusk, lexical activation of "Dean" also played a role in retrieval. Proactive interference also may be involved with those individuals who remembered Joe McCarthy the Yankee Manager instead of the intended Wisconsin Senator; it is noteworthy that Yankee responses were provided by an older cohort than those who responded with the Senator $(B=0.06, p=0.01)$. The case for proactive interference is less strong here since the two individuals do not share category membership. Nevertheless, the earlier Joe McCarthy has an accessibility advantage for some individuals that may either be accompanied by having or not having knowledge of the Senator.

Not all of the significant age-trends indicate a prominent role for the transition phase. Curiously, although there is evidence that the transition phase appears to promote proactive interference, there is no comparable retroactive interference effect. The name errors grouped under "Sixties" for McCarthy (see Table 7) do suggest retroactive interference in that an incorrect later individual was remembered instead of a correct target who had been prominent earlier in time. However, these respondents are reporting individuals who had been experienced at an age older than the transition phase, and not reporting a target individual who had been experienced during their transition phase. Since Paul McCartney is not conceptually related to the Senator Joe McCarthy, a convincing claim that these errors involved an actual interference with a known individual cannot be made. On the other hand, the political astuteness needed to remember aspects of the career of Eugene McCarthy is more suggestive that these individuals would also have knowledge of the well-known communist accuser. ${ }^{6}$ This simply must be one case in which processes other than transition phase effects are at work.

There is also no clear interpretation of the tendency for persons who were older than the transition phase when John Dean (see Table 6) was most well-known to more probably respond with Vague (simply knowing Dean as an unspecified government figure) and Later Time (referring to an aide in Carter or Reagan administrations; $B=0.041, p=0.06$ ) errors. Interpretations become clearer for errors made predominately by people who were younger than the transition phase (Later

6 Considering responses of Eugene McCarthy by themselves does yield a curvilinear trend that approaches significance, with the square of age $B=-0.01, p=0.08$. 
Time errors to McCarthy; $B=-0.039, p<0.01$ ), or not yet alive (Loose Associations to WPA; $B=-0.087, p<0.01$ ), when the events originally occurred (see Table 7). Since these individuals lack direct knowledge of the intended events, having been too young to encode them when they occurred, their responding reflects what they have learned after these events took place. The later time errors to McCarthy were largely based on remembering local Detroit media personalities (J. P. and Jack McCarthy) who were still active at the time of interview. The loose association errors to WPA are made by individuals who have no real idea of what the WPA involved, and who were simply using the acronym to construct a reasonablesounding response (e.g. "World Peace Assembly").

There were also errors to which transition phase effects could have been expected, but did not occur. WWII errors to Tet Offensive, Douglas MacArthur errors to Joe McCarthy, and James Dean errors to John Dean, all involve events that happened at an earlier point in time than the target events, and to which those who experienced the events while at their transition phase should be expected to have a better memory for them. Yet, although older respondents did produce these errors quite often, younger respondents did as well. ${ }^{7}$ These events appear to be those that continue to be kept alive culturally either through schooling, or through popular culture, and younger people may know these incorrect events better than the target events.

\section{General Discussion}

We have found that respondents make many types of errors in expressing their knowledge of public figures and events. These errors appear not as simple attempts to guess wildly (perhaps with the exception of uninterpretable responses), but often show the informed attempts of respondents to provide a correct response. In fact, the quasi-correct "errors," although they reflect responses that were unintended by the investigators, are actually correct responses and show that survey researchers can fail to be sensitive to varieties of genuine knowledge that are different from their own. In addition, in many cases, the errors directly show that respondents were gaining access to relevant information that was available in semantic and lexical memory in the attempt to provide a meaningful response. Related events indicate the extent to which memory is organized along conceptual lines, and that semantic structure plays a role in remembering past episodes (cf., Brown, Shevell, and Rips, 1986). Loose associations point to lexical associations and activation that play a role in respondent report (cf., Brown and McNeill, 1966). These searches through semantic and lexical memory systems may occur in parallel; it is noteworthy that some errors, such as retrieving a memory of Dean Rusk to the cue of John Dean, involve both semantic relatedness and a lexical association. Finally, inversions are remarkable in that respondents are able to retrieve the correct elements that are contained in the event but are reconstructing them in an inverted form, perhaps guided by an overall schematic theme.

Additionally, the present results extend prior research (Schuman et al., 1997) that has shown that respondents are more knowledgeable about those events that

7 In fact, approaching significance was a linear age-trend that indicated that younger people were more likely to produce a Douglas MacArthur error $(B=-0.033, p=0.06)$. 
occurred during the period of life that marks the transition between childhood and adulthood. Errors in the remembering of the past appear more likely to occur when transition phase events interfere with other events either proactively or retroactively, or when, on the basis of schematic knowledge of transition phase events, past events are reconstructed incorrectly or incompletely. Thus, not only are events that occur during the transition phase better remembered and known than events that occur in other phases of the lifespan, but the transition phase can also promote error-prone remembering.

Given that people do know more about transition phase events, explanations of these effects need to center on how the transition phase promotes better memory and retrieval. Rubin (1995) recently offered three classes of hypotheses to account for transition phase effects. Cognitive accounts rely on normal cognitive processes, and as one possibility, would seek to account for transition phase effects as the result of normal, but enhanced, encoding processes that operate throughout the lifespan, but are more likely to occur during the transition phase. Physiological accounts argue that the brain is at its peak performance during the transition phase, with declines in the ability to encode information as one ages. Evolutionary accounts suggest that there is an evolutionary advantage for people to have better memory for transition phase events. One evolutionary account relies on the notion that cultural transmission of important, but otherwise forgotten, past information depends on the memory of a few aged individuals who can relate experiences from many years ago; another account in many ways complements the physiological perspective by suggesting that the brain is at its peak performance during the transition phase because these ages also correspond to the phase of the lifespan when individuals are most reproductively fertile, and reproductive success depends upon an active brain.

Among the cognitive accounts, first or new experiences hypotheses have considerable appeal. For example, Fitzgerald (1988) argued that the transition phase is marked by many more new experiences that contribute to the formation of one's identity in comparison to other life phases, and thus the transition phase is unique in that more experiences are encoded in comparison to other phases. With a slightly different emphasis, Fromholt and Larsen (1991) argued that the transition phase is marked by more life transitional events, such as "leaving school, starting a career, getting married, and have children" than are other life phases, and due to the importance, significance, and consequential character of these transitional events, they would be encoded more thoroughly and are thus more resistant to forgetting. While agreeing with Fromholt and Larsen (1991) that transitional events have a special place in memory, Pillemer and colleagues (Pillemer, Rhinehart, and White, 1986; Pillemer, Goldsmith, Panter, and White, 1988) focus on how transitional events are encoded more distinctly in memory than other events, lending to their better ability to be remembered. Since they are associated with new experiences that cannot be assimilated into pre-existing memory structures, transitional events are encoded as distinctive memories that begin the formation of new memory structures. In turn, within these new structures, transitional memories continue to service as examples to inform appropriate attitudes and behavior for future, but now familiar, similar experiences (see also Jansari and Parkin, 1996; Robinson, 1992a, 1992b).

In some ways, our survey data support these first experience hypotheses, with the best example involving reports on the Tet Offensive. For individuals who experienced the Vietnam War during their transition phase, the events of Vietnam would constitute their first war experiences; on the other hand, for those 
who experienced Vietnam after the transition phase, there would be earlier war memories (e.g. the Korean War) that would lend the events of Vietnam to be more familiar and less distinctive. Thus, those individuals who experienced the Vietnam War during their transition phase are more accurate than other individuals in reporting on the Tet Offensive (Schuman et al., 1997), whereas, as shown in the present results, those persons who experienced the Korean War during their transition phase would be more likely to refer to the Tet Offensive as an event from the Korean War. Less supportive of first experience accounts, but certainly not completely inconsistent with them, are our findings that the transition phase has also played a role in respondents remembering characteristics of Dean Rusk when cued with John Dean, or the Yankee Manager Joe McCarthy instead of the Wisconsin Senator. In these cases, it is not compelling to argue that the earlier transition phase events led the later events to become much less distinctive; John Dean and the Senator are quite unique personalities in the American experience and thus should serve as first experiences to all who have known them. Yet, it may be the case that the Dean Rusk responses resulted from response competition between two first experiences (one of Dean Rusk and the other of John Dean) that had received some level of activation within semantic and lexical memory systems, and it is quite possible that the apparent sports fans who remembered the Yankee manager never paid attention to political events. The accessibility advantages of first experiences could also lead them to retroactively interfere with earlier events as well.

The inversion and confabulation errors that we found with transition phase reports pose challenges to all of the mentioned accounts of better transition phase memory. Since the physiological and evolutionary accounts are compelling only as explanations of better memory, there would need to be modification to explain less than adequate remembering of transition phase events. Regarding the first experiences hypotheses, the overall pattern of these errors suggested the presence of a reconstructive process that was based on the memory for a schematic theme. They also tended to be produced by individuals who were at the youngest transition phase ages. Stewart and Healy (1989) argued that late childhood and early adolescence are marked by learning about the outside environment and about those aspects that best characterize the different entities that make up the world. By this account, events that happen in the early part of the transition phase may only be incompletely known, eventually leading to many of the types of reconstructive errors we have observed. Thus, the nature of first experiences may not be monolithic during the entire transition phase, but rather, may differ depending on whether the events are experienced during late childhood or early adulthood. According to Stewart and Healy, identity formation does not enter the fore until around midstream during the transition phase.

Of our findings, the discovery of inversion errors surprised us the most. The transition phase inversions observed with Joe McCarthy and the Tet Offensive are an indication that the greater ability to recall the components of transition phase events is no guarantee of accuracy. There is something quite dramatic, as in the case of Joe McCarthy, about being remembered as possessing those properties which one had abhorred and accused others of possessing. It is difficult to conceive of a more fundamental error.

One advantage with this research was our ability to know the true state of affairs, thus allowing us to determine when a response is in error. In most of the 
work on autobiographical memory, including much of the work that illustrates transition phase effects, there is no ability for the researcher to test the accuracy of what people report. We can only speculate that inversion and other kinds of errors are not uncommon in the remembering of unverifiable personal past events as well. Just as John Dean had not been totally faithful in recounting his past (Neisser, 1981), our findings point to the dramatic ways in which the remembering of our own pasts may be fraught with error.

\section{References}

Bishop, G. F., Tuchfarber, A. J., and Oldendick R. W. (1986). Opinions of fictitious issues: The pressure to answer survey questions. Public Opinion Quarterly, 50, 240-250.

Brown, N. R. Shevell, S. K. and Rips, L. J. (1986). Public memories and their personal context. In D. C. Rubin (Ed.), Autobiographical memory (pp. 137-158). New York: Cambridge University Press.

Brown, R. and McNeill, D. (1966). The "tip of the tongue" phenomenon. Journal of Verbal Learning and Verbal Behaviour, 5, 325-377.

Duncan, L. E. and Agronick, G. S. (1995). The intersection of life stage and social events: personality and life outcomes. Journal of Personality and Social Psychology, 69, 558-568.

Fitzgerald, J. M. (1988). Vivid memories and the reminiscence phenomenon: The role of a self narrative. Human Development, 31, 261-273.

Fitzgerald, J. M. and Lawrence, R. (1984). Autobiographical memory across the lifespan. Journal of Gerontology, 39, 692-699.

Franklin, H. C. and Holding, D. H. (1977). Personal memories at different ages. Quarterly Journal of Experimental Psychology, 29, 527-532.

Fromholt, P. and Larsen, S. F. (1991). Autobiographical memory in normal aging and primary degenerative dementia. Journal of Gerontology: Psychological Sciences, 46, P85-91.

Jansari, A. and Parkin, A. J. (1996). Things that go bump in your life: Explaining the reminiscence bump in autobiographical memory. Psychology and Aging, 11, 85-91.

Neisser, U. (1981). John Dean's memory: A case study. Cognition, 9, 1-22.

Neisser, U. (1982). Snapshots or benchmarks? In U. Neisser (Ed.), Memory observed: Remembering in natural contexts (pp. 43-48). San Francisco: Freeman.

Neisser, U. (1988). Commentary. Human Development, 31, 271-273.

Pillemer, D. B., Rhinehart, E. D. and White, S. H. (1986). Memories of life transitions: The first year in college. Human Learning, 5, 109-123.

Pillemer, D. B., Goldsmith, L. R., Panter, A. T., and White, S. H. (1988). Very long-term memories of the first year in College. Journal of Experimental Psychology: Learning, Memory, and Cognition, 14, 709-715.

Robinson, J. A. (1992a). Autobiographical memory. In M. Gruneberg and P. Morris (Eds.), Aspects of memory. Volume 1: The practical aspects (pp. 223-251). New York: Routledge.

Robinson, J. A. (1992b). First experience memories: Contexts and functions in personal histories. In M. A. Conway, D. C. Rubin, H. Spinnler, and W. A. Wagenaar (Eds.), Theoretical perspectives on autobiographical memory (pp. 223-239). The Netherlands: Kluwer.

Robinson, J. A. and Hawpe, L. (1986). Heuristic uses of narrative thinking. In T. R. Sarbin (Ed.), Narrative thinking: The storied nature of human conduct. New York: Praeger.

Rubin, D. C. (1995, July). Ruminations on reminiscence. Paper presented at the meeting of the Society for Applied Research in Memory and Cognition, Vancouver, BC. 
Rubin, D. C., Wetzler, S. E., and Nebes, R. D. (1986). Autobiographical memory across the lifespan. In D. C. Rubin (Ed.), Autobiographical memory (pp. 202-221). New York: Cambridge University Press.

Schuman, H., Belli, R. F., and Bischoping, K. (1997). The generational basis of historical knowledge. In J. W. Pennebaker, D. Paez, and B. Rimé (Eds.), Collective memory of political events: Social psychological perspectives (pp. 47-77). Hillsdale, NJ: Erlbaum.

Schuman, H. and Presser, S. (1981). Questions and answers in attitude surveys. New York: Academic Press.

Schuman, H., Rieger, C., and Gaidys, V. (1994). Collective memories in the United States and Lithuania. In N. Schwarz and S. Sudman (Eds.), Autobiographical memory and the validity of retrospective reports (pp. 313-333). New York: Springer-Verlag.

Schuman, H. and Scott, J. (1989). Generations and collective memories. American Sociological Review, 54, 359-381.

Stewart, A. J. and Healy, J. M. Jr. (1989). Linking individual development and social change. American Psychologist, 44, 30-42.

Zola-Morgan, S., Cohen, N. J., and Squire, L. R. (1983). Recall of remote episodic memory in amnesia. Neuropsychologia, 21, 487-500. 